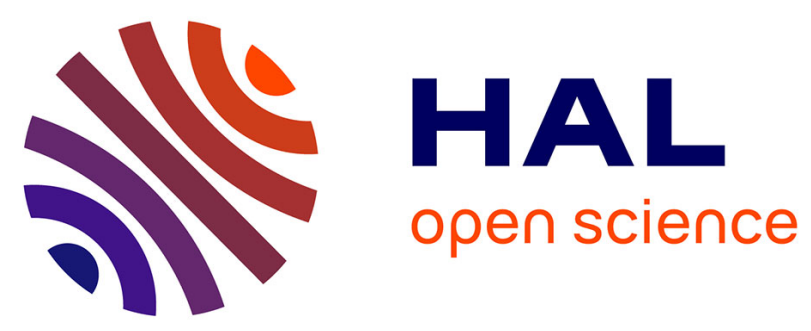

\title{
Cyclic strain promotes shuttling of PYK2/Hic-5 complex from focal contacts in osteoblast-like cells.
}

Alain Guignandon, Nadia Boutahar, Aline Rattner, Laurence Vico, Marie-Hélène Lafage-Proust

\section{- To cite this version:}

Alain Guignandon, Nadia Boutahar, Aline Rattner, Laurence Vico, Marie-Hélène Lafage-Proust. Cyclic strain promotes shuttling of PYK2/Hic-5 complex from focal contacts in osteoblastlike cells.. Biochemical and Biophysical Research Communications, 2006, 343 (2), pp.407-14. 10.1016/j.bbrc.2006.02.162 • ujm-00123390

\section{HAL Id: ujm-00123390}

\section{https://hal-ujm.archives-ouvertes.fr/ujm-00123390}

Submitted on 10 Jan 2007

HAL is a multi-disciplinary open access archive for the deposit and dissemination of scientific research documents, whether they are published or not. The documents may come from teaching and research institutions in France or abroad, or from public or private research centers.
L'archive ouverte pluridisciplinaire HAL, est destinée au dépôt et à la diffusion de documents scientifiques de niveau recherche, publiés ou non, émanant des établissements d'enseignement et de recherche français ou étrangers, des laboratoires publics ou privés. 


\title{
Cyclic strain promotes shuttling of PYK2/Hic-5 complex from focal contacts in osteoblast-like cells
}

\author{
Alain Guignandon*¹, Nadia Boutahar*, Aline Rattner, \\ Laurence Vico and Marie-Hélène Lafage-Proust
}

INSERM E366, St Etienne, F-42023 France; Laboratoire de Biologie du Tissu Osseux (LBTO), St Etienne, Université Jean Monnet, F-42023 France,

IFR62 Laennec, Lyon, F-69372, France

* The two first authors equally contributed to the work

${ }^{1}$ corresponding author: Alain Guignandon, INSERM E366,

Laboratoire de Biologie du Tissu Osseux, Faculté de Médecine, 15, rue Ambroise Paré, F-42023 SAINT-ETIENNE cedex 02-France.

Phone : (33) 4774214 23, Fax: (33) 4775755 72,

Email: Alain.Guignandon@univ-st-etienne.fr 


\begin{abstract}
We showed that cyclic strain (CS) of osteoblastic cells induced tyrosine phosphorylation of two homologous tyrosine kinases FAK and PYK2 and of two homologous adaptor proteins Paxillin and Hic5, with similar kinetics. Immunostaining showed that all four proteins where localised to focal contacts in controls. In contrast, the dynamics of their subcellular localisation observed after CS differed. While FAK and paxillin remained at the focal contact, Hic-5 and PYK2 translocated outside ventral focal contacts as early as 30 min after CS and were sequestered by the cytoskeleton. Co-immunoprecipitation showed that the association PYK2/Hic-5 and PYK2/FAK increased with time after strain while that of Paxillin and Hic-5 decreased. Altogether these results suggested that CS regulate focal contact activity in osteoblasts by modulating PYK2-containing complexes in particular by shuttling out of the focal contact the adaptor Hic-5 and favouring the anchorage of FAK within contacts.
\end{abstract}

Keywords: PYK2; FAK; Hic-5; Paxillin; focal contact; osteoblasts; cyclic strain. Running Title: PYK2/Hic-5 and PYK2/FAK association under cyclic strain 


\section{INTRODUCTION}

It is now well evidenced that mechanical strain plays a major role in the maintenance of bone mass. Osteoblasts, the bone forming cells appear to be the key effectors of osteogenic mechanical stimuli and in vivo studies suggested that loading-induced increase in bone formation was related to an increase in osteoblast recruitment $\left({ }^{1}\right)$. However, the molecular mechanisms that mediate this response are not clearly identified. Several lines of evidence suggested that integrins, which represent a convergence point of several signals and transmit tension to extracellular matrix (ECM) and to the intracellular structures, including the nucleus, are essential for the signal transduction of a mechanical stimulus $\left({ }^{2}\right)$. In a previous study, we showed that cyclic stretching of osteoblasts induced an increase in size and number of adhesion plaques, immuno-stained with phosphotyrosine antibodies, demonstrating the involvement of integrins in osteoblastic mechanotransduction $\left({ }^{3}\right)$. Futhermore, we showed that the strain-induced mitogenic response of osteoblast-like cells depended upon ERK activation under the control of FAK and PYK2 $\left({ }^{4}\right)$, two yrosine kinases which colocalize to the adhesion plaques $\left({ }^{5}\right)$. FAK and PYK2 are closely related in their overall structure with about $46 \%$ sequence identity (65\% similarity) over their entire length $\left({ }^{6}\right)$. They are both phosphorylated by integrin binding $\left({ }^{7},{ }^{8},{ }^{9}\right)$; however, PYK2 can also be activated by intracellular calcium changes. Interestingly, it was recently shown in F9 cells that adhesiondependent activation of ERK is mediated by FAK-paxillin binding $\left({ }^{10}\right)$. Paxillin is an adaptor molecule of 559 amino-acids which contains numerous potential protein-protein binding sites, including proline-rich regions, SH2 binding sites and four LIM domains $\left({ }^{11},{ }^{12},{ }^{13}\right)$. Beside FAK, paxillin interacts with several other protein such as Src family-SH3 domains $\left({ }^{14}\right)$ and vinculin $\left({ }^{15}\right)$. Hic-5, a protein with high homology with paxillin was shown to share some of its binding partners such as FAK, PYK2, Csk, vinculin, and PTP-PEST $\left({ }^{16}\right)$. Hic-5 can be 
phosphorylated on tyrosine residues, although the sites of tyrosine phosphorylation in paxillin are not conserved in Hic-5 $\left({ }^{17}\right)$. Interestingly, unlike their respective homologues paxillin and FAK, both Hic-5 and PYK2 are not exclusively found at the adhesion plaque. Indeed, Hic-5, which bears a NES sequence, was reported to shuttle to the nucleus under various stimuli $\left({ }^{18}\right)$, while PYK2 was observed into both the nucleus and the cytoplasm. It has been reported recently in smooth muscle cells, that HIC-5 is sequestered by actin-stress fibers under mechanical strain $\left({ }^{19}\right)$. These differential subcellular localisations suggested that these focal adhesion proteins might play a role in mechanotranduction (19) and transcription of target genes $\left({ }^{20}\right)$. In this context, our aim was to further analyse the kinetics of activation and subcellular localisation of PYK2 and HIC-5 in osteoblast-like cells submitted to mitogenic mechanical strain.

\section{MATERIALS and METHODES}

\section{Materials}

Horseradish peroxidase-conjugated goat anti-rabbit (P0448) and Horseradish peroxidaseconjugated horse anti-mouse (P0447) antibodies were obtained from DAKO. Anti-Ptyr (PY99) and anti-FAK (H-1) antibodies were obtained from Santa Cruz Biotechnology (Santa Cruz, CA).The anti-PYK2 mouse monoclonal antibody was obtained from Transduction Laboratories (Montluçon, France). The anti-paxillin mouse monoclonal was obtained from Upstate Biotechnology (Mundolsheim, France) and the anti-Hic-5 mouse monoclonal clone 34 was obtained from BD Biosciences Pharmingen (Le Pont-De-Claix, France). ECL detection reagents were purchased from Pierce (Montluçon, France). Stripping solution ReBlot Plus was obtained from Chemicon International (Temecula, CA)

\section{Cell culture}


We used ROS 17/2.8 osteoblast-like cells, a well-defined cell line $\left({ }^{21}\right)$ with the characteristics of mature osteoblasts (alkaline phosphatase activity, osteocalcin and type I collagen expression, and ability to mineralize), and the MC3T3-E1 mouse osteoblastic cell line. Cells were grown in humidified atmosphere with $5 \% \mathrm{CO}_{2}$ at $37^{\circ} \mathrm{C}$. ROS $17 / 2.8$ cells were cultured in DMEM, and MC3T3-E1 cells in $\alpha$-MEM, both supplemented with 10\% FCS, 2mM Lglutamine, $100 \mathrm{U} / \mathrm{ml}$ penicillin and $0.1 \mathrm{mg} / \mathrm{ml}$ streptomycin. After reaching a subconfluent state, cells were trypsinized with $1 \mathrm{X}$ trypsin-EDTA, counted and plated.

\section{Cyclic deformation}

The Flexcell Strain Unit Fx-3000 (Flexcell Corp, McKeesport, PA) was used for application of mechanical stretch to osteoblasts $\left({ }^{22}\right)$. Cells were plated in six well tissue culture dishes with type I collagen-coated flexible silicone bottoms at $1.10^{4}$ cells per $\mathrm{cm}^{2}$ density for seventy two hours after seeding, cells were serum-starved overnight and then subjected to mechanical deformation. Mechanical deformation was induced with a Flexercell Strain Unit (Bioflex, Flexcell Corp, McKeesport, PA), which consists in a vacuum manifold regulated by solenoid valves that are controlled by a computer timer program. Six buttons insert into each plate, each allowing a uniform magnitude of the strain across $85 \%$ of the surface of a flexible well. For these experiments, an 80 kilopascals negative pressure was applied to each culture plate, through an air pump, bottoms were deformed to a known percentage of elongation and then releasing the membranes to their original shape. The experimental regimens used in this study delivered $1 \%$ elongation and at a rate of 15 cycles/min (2s deformation period followed by a 2s neutral position). Cells remained adherent, and the deformation of the membrane is directly transmitted to cells. Cells grown on unstretched Bioflex plates were used as controls.

\section{Immunoprecipitation}

Cells were lysed in buffer (25 mM tris PH 7.5, 150mM NaCl, 1\% IGEPAL, 1\% sodium deoxycholate, $0.1 \%$ SDS, 50mM sodium fluoride, 10Mm Sodium Pyrophosphate, 1mM 
AEBSF, 0.1 Unit/ml aprotinin, $10 \mu \mathrm{g} / \mathrm{ml}$ leupeptin, 1mM Sodium orthovanadate). Lysates were clarified by centrifugation at $14,000 \mathrm{rpm}$ for $30 \mathrm{~min}$. Supernatant were transferred to fresh tubes. Protein concentration of lysates was determined with the bicinchoninic acid assay (Pierce, Rockford, IL).

Immunoprecipitations were typically performed with $1-2 \mathrm{mg}$ of cell lysate and $2 \mu \mathrm{g}$ of purified monoclonal or polyclonal antibody. After incubation at $4^{\circ} \mathrm{C}$ for $2 \mathrm{~h}$ on rotating device, immune complexes were precipitated at $4^{\circ} \mathrm{C}$ overnight on rotating device by using protein $\mathrm{A}$ sepharose (Sigma, St-Quentin Fallavier, France). Immunoprecipitates were washed three times with lysis buffer and extracted in 2X SDS-PAGE sample buffer (125mM Tris-HCl,pH 6.8, 4\% SDS, $20 \%$ glycerol, $10 \% \beta$-mercaptoethanol, $0.025 \%$ bromophenol blue) by $5 \mathrm{~min}$ boiling and electrophoresed by SDS-PAGE and analysed by western blotting.

\section{Western blot analysis}

After SDS-PAGE, proteins were transferred to nitrocellulose membrane (BioRad,Hercules,CA). After transfer, membranes were blocked with 5\% non-fat dried milk in PBS, pH 7.4, and incubated overnight at $4^{\circ} \mathrm{C}$ with the anti-p-Tyr (PY99) , anti-FAK, antiPYK2, anti-Paxillin ,or anti-Hic-5 antibodies, $0.1 \mu \mathrm{g} / \mathrm{ml}$. Membranes were washed three times with TBS (0.1\% Tween 20) and then incubated with secondary antibodies (peroxidaseconjugated goat anti-rabbit,1:2000 or horse anti-mouse,1:6000) for $1 \mathrm{~h}$ at room temperature. After washing three times with TBS, 0.1\% Tween 20, the immunoreactive bands were visualized using ECL detection reagents. Immunoblot were stripped with mild antibody stripping solution and reprobed. Levels of tyrosine phosphorylation and the amounts of protein were quantified using a software Scion Image program for densitometry analysis (Scion Corporation, suite H, Maryland). Each band was normalized to the total protein level in the respective sample. Immunoblots shown in this paper are representative of at least two separate experiments. 


\section{Immunofluorescence image analysis.}

Immunostaining was performed on stretched and control cells at various time points after the end of the stimulation. Cells were fixed in $4 \%$ paraformaldehyde for $10 \mathrm{~min}$, washed with cold PBS and permeabilized with $0.1 \%$ triton X-100 in PBS for 2 min. Anti-FAK, anti-PYK2, anti-Paxillin, or anti- Hic-5 antibodies (1:100 in PBS/BSA 1\%) were applied for $1 \mathrm{H}$ at $37^{\circ} \mathrm{C}$ and cells were rewashed in PBS on a rocking platform. Cells were incubated with fluorescein isothiocyanate (FITC)-conjugated goat anti-mouse or anti-rabbit IgG (1:100 in PBS/BSA 1\%) for $1 \mathrm{~h}$ at $37^{\circ} \mathrm{C}$. Immunostaining was observed with fluorescence microscope (Leica DMRB, Lyon, France) and acquired with a cooled CCD camera (CoolSNAP.fx, Roper Scientific, Evry, France) with Metaview system software (Universal Imaging Corp, Downingtown, PA, USA).

\section{RESULTS}

\section{Tyrosine phosphorylation of pp125 ${ }^{\mathrm{FAK}}$, PYK2, Paxillin and HIC-5 induced by mitogenic} cyclic strain.

Tyrosine phosphorylation of cellular proteins was examined by immuno-blotting using antiphosphotyrosine monoclonal antibody. In response to cyclic strain, a time-dependent tyrosine phosphorylation of several proteins was observed in rat osteosarcoma cell line (ROS 17/2.8) cells (Fig 1A) as well as in the mouse osteoblastic cell line MC3T3-E1 (data not shown). We found 2 clusters of proteins detected at $110-125 \mathrm{kDa}$ and at 50 and $65 \mathrm{kDa}$ that might correspond to FAK/PYK2 and paxillin/Hic-5, respectively. The increase in tyrosine phosphorylation level was detected as early as the end of strain and was extended up to $4 \mathrm{~h}$ for both clusters. In order to identify more precisely the phosphorylation time course of the four

focal contact proteins, we first performed an immunoprecipitation of $\mathrm{pp} 125^{\mathrm{FAK}}$ and PYK2 from lysates of static and stretched cells and probed with anti-phosphotyrosine antibody. FAK 
phosphorylation increased in a time dependent manner (Fig 1B). As for PYK2, its phosphorylation increased immediately after strain (Fig 1C) and persisted after $4 \mathrm{~h}$. We then immunoprecipitated Paxillin and Hic-5 from lysates of static and stretched cells and probed with anti-phosphotyrosine antibody. High levels of Paxillin phosphorylation began immediately after strain (Fig 1D) as well as Hic-5 and remained at the same level at $4 \mathrm{~h}$ (Fig $1 \mathrm{E})$.

\section{Distinct localisations of focal contact proteins induced by cyclic strain.}

As the time course of phosphorylation of the four focal contact proteins was roughly similar, we focalized on the relocalisation and physical interactions of these proteins under cyclic strain. The homologous proteins paxillin and Hic-5 exhibited different subcellular localisations induced by mechanical strain. Paxillin immunofluorescence staining essentially localized to focal adhesion plaques and remained unchanged in strained compared to control cells (Fig 2A). In contrast, Hic-5 immunostaining showed a significant fraction of Hic-5 protein shuttling from the focal contact to the cytoplasm 30 min. after strain and appeared associated with fibrillar structures of the cytoskeleton after 240 min (Fig. 2C). FAK remained at the focal contact regardless of the time point observed (Fig. 2B). In contrast, PYK2 shuttled from focal contact to perinuclear regions of the cytoplasm 30 min after strain, this diffuse cytoplasmic localization observed under basal conditions was resumed 240 min after strain (Fig. 2D). In order to illustrate more precisely the Hic-5 localisation after cyclic strain, we visualised Hic-5 in the nuclear plane 30' after strain (Fig. 3A) and found that Hic-5 was not present is the nucleus, moreover in the same field, punctuated staining were detected in apical structures of the cells (Fig. 3B) demonstrating that central staining observed in Fig. 2B \& 2C could not be attributed to a nuclear translocation of Hic-5 under strain. Using a larger 
magnification, we demonstrated that Hic-5 was clearly associated with fibrilllar structures 240’ after strain (white arrows) (Fig. 3C).

\section{Interactions between focal contact proteins are modified by cyclic strain.}

In the present study, co-immunoprecipitation experiments evidenced a strong and constant interaction between Paxillin and PYK2 regardless of the mechanical condition (Fig. 4A). Association between PYK2 and Hic-5 increased in a time-dependent manner under strain (Fig 3C) as well as the association of PYK2 and FAK (Fig. 4D). These associations were specifically induced by cyclic strain because as demonstrated by the absence of complexes in unstrained cells. Conversely, the association between Hic-5 and paxillin decreased during the 240 minutes of recovery after strain (Fig 4B). These results suggest that paxillin and FAK which are both phosphorylated under mechanical stimulus remained localized to the focal contact. In contrast, a fraction of PYK2 and Hic-5 shuttled out of focal contact inducing a release of Hic-5 from paxillin. Interestingly, in the same time, we observed a strengthening of PYK2/FAK association under mechanical strain (Fig. 4D) suggesting a central role of PYK2 in osteoblasts submitted to cyclic strain.

\section{DISCUSSION}

We previously showed that tyrosine kinases FAK and PYK2 are critical for strain-induced increase in osteoblastic proliferation (3). However, knowing the complexity of the relationships between their signalling partners, further analyses were needed to begin to decipher their respective role in osteoblastic mechanotransduction pathways. In endothelial cells exposed to hemodynamic shear stresses, the spatial reorganization of focal adhesion proteins associated with mechanotransduction plays a major role, especially because the forces vary greatly over subcellular distances $\left({ }^{23}\right)$. Thus, we investigated spatiotemporal 
components of signalling molecules such as FAK, Paxillin and their homologues PYK2 and Hic-5 in osteoblasts.

In the present study, beside FAK and PYK2, we found that paxillin and its homologue Hic-5 were also tyrosine-phosphorylated under mechanical strain. These four proteins localised to focal contacts under basal conditions and cyclic strain led to a shuttling of a Hic-5/PYK2 complex out of the focal contacts while FAK and paxillin remained to the focal contacts throughout the time points considered. Interestingly, the Hic-5/paxillin association decreased under mechanical strain. This suggested that, in unstrained cells, paxillin sequestered Hic-5 at the focal adhesion sites and that mechanical strain led to a release of Hic-5 from paxillin. Hic5 and paxillin share many similar binding partners, but it was shown that Hic-5 antagonizes paxillin functions. For instance, the LD3 motif of Hic-5, which corresponds to the paxillin LD4 motif, is required for Hic-5 mediated inhibition of cell spreading, possibly by sequestering FAK from paxillin $\left({ }^{24}\right)$. Once associated with cytoskeletal structure such as actin stress fiber as clearly demonstrated by Kim-Kaneyama et al. (19), Hic-5 down regulates factin contractility by its association with GIT1 an Arf GTPase activating protein $\left({ }^{25}\right)$ known to switch from cytoplasmic location to f-actin fibers $\left({ }^{26}\right)$. As stress fibers polymerization is a common biological response to mechanical stimulation $\left({ }^{27}\right)$, it can be speculated that shuttling of Hic-5 from focal adhesion to cytoskeleton increases f-actin turnover.

It is also known that Hic-5 can transfer from focal adhesions to the nucleus in response to $\mathrm{H}_{2} \mathrm{O}_{2}$ in MC3T3 osteoblast-like cells $\left({ }^{28}\right)$. Once localized in the nucleus, Hic-5 was involved of in endogenous $c$-fos induction by $\mathrm{H}_{2} \mathrm{O}_{2}$ in osteoblasts and stromal cells lines (28). Finally, Hic-5 was reported to bind to steroid receptors and act as a transcription coactivator in transient reporter assays $\left({ }^{29},{ }^{30}\right)$. As we demonstrated that Hic-5 is never localized within the nucleus (Fig. 4A) after cyclic strain, mechanical stimulation had a specific role in inducing Hic-5 association with the cytoskeleton. Identification of 12 Hic-5 isoforms $\left({ }^{31}\right)$ may explain 
the range of biological responses attributed to Hic-5 and complicates interpretation of its role in mechanotransduction.

A fraction of PYK2 is associated Hic-5 nevertheless a large fraction of PYK2 remained in the cytoplasm or associated with focal contact proteins such as FAK, explaining that it was not possible to identify PYK2 associated with fibrillar structures of cytoskeleton such as f-actin fibers. We observed a strengthening of PYK2/FAK association under mechanical strain and in a previous study we found a critical role of PYK2 in the late activation of the MAP Kinases cascades (3). Interestingly, it was previously shown that FAK is a PYK2 substrate and that the tyrosine phosphorylation of FAK by PYK2 occurs at sites different from those necessary for the activation of the Grb2/Sos/MAPkinase pathway (5). The reinforcement of PYK2/FAK complex might facilitate phosphorylation of FAK and recruitment of other signalling proteins within focal contact such as Src or Fyn $\left({ }^{32}\right)$.

In summary, we showed that mechanical strain activated two homologue tyrosine kinases, PYK2 and FAK that are both involved in integrin signalling. Moreover, PYK2, which can also be activated in response to a variety of agonists, hormones, or ion channel activation, was found to be specifically associated to different proteins under strain depending of cell compartments. We showed PYK2 associated with Hic-5 in cytoplasmic compartement and with FAK at focal adhesion sites in strained cells (Fig. 4). The redistribution of focal contact proteins under mechanical strain suggested a new way of regulation that implied PYK2 both in cytoplasm compartment by severing the paxillin inhibitor Hic-5 and in focal contact by complexing and activating FAK.

In conclusion, as more and more data have been accumulated concerning intracellular signalling pathways of mechanotransduction in osteoblasts $\left({ }^{33}, 7\right)$, roles of individual molecules tend to become more and more obscure. Thus, some integrated studies are desirable to clarify the complicated intracellular signalling pathways as a whole. PYK2 may be an 
important newcomer in the mechanotranduction field, as it was emphasized for endothelial cells (23), because it may be located at a critical crossing point of multiple signalling pathways.

\section{ACKNOWLEDGEMENTS}

This study was supported by ERISTO (European Research in Space and Terrestrial Osteoporosis) contract number 14232/00/NL/SH and INSERM (Institut National de la Santé et de la Recherche Médicale). 


\section{References}

$\left.{ }^{1}\right]$ S. Bourrin, C. Genty, S. Palle, C. Gharib, and C. Alexandre, Adverse effects of strenuous exercise: a densitometric and histomorphometric study in the rat, J Appl Physiol 76 (1994) 1999-2005.

[2] A. J. Maniotis, C. S. Chen, and D. E. Ingber, Demonstration of mechanical connections between integrins, cytoskeletal filaments, and nucleoplasm that stabilize nuclear structure, Proc Natl Acad Sci U S A 94 (1997) 849-854.

$\left[{ }^{3}\right]$ N. Boutahar, A. Guignandon, L. Vico, and M. H. Lafage-Proust, Mechanical strain on osteoblasts activates autophosphorylation of focal adhesion kinase and proline-rich tyrosine kinase 2 tyrosine sites involved in ERK activation, J Biol Chem 279 (2004) 30588-30599.

$\left.{ }^{4}\right]$ A. Guignandon, O. Akhouayri, Y. Usson, A. Rattner, N. Laroche, M. H. Lafage-Proust, C. Alexandre, and L. Vico, Focal contact clustering in osteoblastic cells under mechanical stresses: microgravity and cyclic deformation, Cell Commun Adhes 10 (2003) 69-83.

[5] X. Li, R. C. Dy, W. G. Cance, L. M. Graves, and H. S. Earp, Interactions between two cytoskeleton-associated tyrosine kinases: calcium-dependent tyrosine kinase and focal adhesion tyrosine kinase, J Biol Chem 274 (1999) 8917-8924.

[ $\left.{ }^{6}\right]$ H. Sasaki, K. Nagura, M. Ishino, H. Tobioka, K. Kotani, and T. Sasaki, Cloning and characterization of cell adhesion kinase beta, a novel protein-tyrosine kinase of the focal adhesion kinase subfamily, J Biol Chem 270 (1995) 21206-21219

[7] M. Wozniak, A. Fausto, C. P. Carron, D. M. Meyer, and K. A. Hruska, Mechanically strained cells of the osteoblast lineage organize their extracellular matrix through unique sites of alphavbeta3-integrin expression, J Bone Miner Res 15 (2000) 1731-1745.

${ }^{8}{ }^{3}$ A. Astier, H. Avraham, S. N. Manie, J. Groopman, T. Canty, S. Avraham, and A. S. Freedman, The related adhesion focal tyrosine kinase is tyrosine-phosphorylated after beta1integrin stimulation in B cells and binds to p130cas, J Biol Chem 272 (1997) 228-232.

$\left[{ }^{9}\right]$ J. Li, H. Avraham, R. A. Rogers, S. Raja, and S. Avraham, Characterization of RAFTK, a novel focal adhesion kinase, and its integrin-dependent phosphorylation and activation in megakaryocytes, Blood 88 (1996) 417-428.

$\left[{ }^{10}\right]$ M. C. Subauste, O. Pertz, E. D. Adamson, C. E. Turner, S. Junger, and K. M. Hahn, Vinculin modulation of paxillin-FAK interactions regulates ERK to control survival and motility, J Cell Biol 165 (2004) 371-381.

$\left[{ }^{11}\right]$ C. E. Turner, and J. T. Miller, Primary sequence of paxillin contains putative SH2 and SH3 domain binding motifs and multiple LIM domains: identification of a vinculin and pp125Fak-binding region, J Cell Sci 107 (Pt 6) (1994) 1583-1591.

$\left[{ }^{12}\right]$ M. C. Brown, M. S. Curtis, and C. E. Turner, Paxillin LD motifs may define a new family of protein recognition domains, Nat Struct Biol 5 (1998) 677-678. 
$\left[{ }^{13}\right]$ C. E. Turner, Paxillin and focal adhesion signalling, Nat Cell Biol 2 (2000) E231-236.

$\left[{ }^{14}\right]$ Z. Weng, J. A. Taylor, C. E. Turner, J. S. Brugge, and C. Seidel-Dugan, Detection of Src homology 3-binding proteins, including paxillin, in normal and v-Src-transformed Balb/c 3T3 cells, J Biol Chem 268 (1993) 14956-14963.

$\left.{ }^{15}\right]$ M. C. Brown, J. A. Perrotta, and C. E. Turner, Identification of LIM3 as the principal determinant of paxillin focal adhesion localization and characterization of a novel motif on paxillin directing vinculin and focal adhesion kinase binding, J Cell Biol 135 (1996) 11091123.

$\left.{ }^{16}\right]$ S. M. Thomas, M. Hagel, and C. E. Turner, Characterization of a focal adhesion protein, Hic-5, that shares extensive homology with paxillin, J Cell Sci 112 (Pt 2) (1999) 181-190.

$\left[{ }^{17}\right]$ M. Matsuya, H. Sasaki, H. Aoto, T. Mitaka, K. Nagura, T. Ohba, M. Ishino, S. Takahashi, R. Suzuki, and T. Sasaki, Cell adhesion kinase beta forms a complex with a new member, Hic-5, of proteins localized at focal adhesions, J Biol Chem 273 (1998) 1003-1014.

$\left[{ }^{18}\right]$ M. Shibanuma, J. R. Kim-Kaneyama, K. Ishino, N. Sakamoto, T. Hishiki, K. Yamaguchi, K. Mori, J. Mashimo, and K. Nose, Hic-5 communicates between focal adhesions and the nucleus through oxidant-sensitive nuclear export signal, Mol Biol Cell 14 (2003) 1158-1171.

$\left[{ }^{19}\right]$ J. R. Kim-Kaneyama, W. Suzuki, K. Ichikawa, T. Ohki, Y. Kohno, M. Sata, K. Nose, and M. Shibanuma, Uni-axial stretching regulates intracellular localization of Hic-5 expressed in smooth-muscle cells in vivo, J Cell Sci 118 (2005) 937-949.

$\left[{ }^{20}\right]$ A. E. Aplin, and R. L. Juliano, Regulation of nucleocytoplasmic trafficking by cell adhesion receptors and the cytoskeleton, J Cell Biol 155 (2001) 187-191.

$\left[{ }^{21}\right]$ R. J. Majeska, S. B. Rodan, and G. A. Rodan, Parathyroid hormone-responsive clonal cell lines from rat osteosarcoma, Endocrinology 107 (1980) 1494-1503.

$\left.{ }^{22}\right]$ A. J. Banes, J. Gilbert, D. Taylor, and O. Monbureau, A new vacuum-operated stressproviding instrument that applies static or variable duration cyclic tension or compression to cells in vitro, J Cell Sci 75 (1985) 35-42..

$\left[{ }^{23}\right]$ P. F. Davies, Multiple signaling pathways in flow-mediated endothelial mechanotransduction: PYK-ing the right location, Arterioscler Thromb Vasc Biol 22 (2002) 1755-1757.

$\left[{ }^{24}\right]$ N. Nishiya, K. Tachibana, M. Shibanuma, J. I. Mashimo, and K. Nose, Hic-5-reduced cell spreading on fibronectin: competitive effects between paxillin and Hic-5 through interaction with focal adhesion kinase, Mol Cell Biol 21 (2001) 5332-5345.

$\left.{ }^{25}\right]$ N. Nishiya, T. Shirai, W. Suzuki, and K. Nose, Hic-5 interacts with GIT1 with a different binding mode from paxillin, J Biochem (Tokyo) 132 (2002) 279-289.

$\left.{ }^{26}\right]$ Y. Shikata, K. G. Birukov, A. A. Birukova, A. Verin, and J. G. Garcia, Involvement of site-specific FAK phosphorylation in sphingosine-1 phosphate- and thrombin-induced focal adhesion remodeling: role of Src and GIT, Faseb J 17 (2003) 2240-2249. 
$\left.{ }^{[27}\right]$ S. Albinsson, I. Nordstrom, and P. Hellstrand, Stretch of the vascular wall induces smooth muscle differentiation by promoting actin polymerization, J Biol Chem 279 (2004) 34849-34855.

$\left[{ }^{28}\right]$ M. Shibanuma, J. R. Kim-Kaneyama, K. Ishino, N. Sakamoto, T. Hishiki, K. Yamaguchi, K. Mori, J. Mashimo, and K. Nose, Hic-5 communicates between focal adhesions and the nucleus through oxidant-sensitive nuclear export signal, Mol Biol Cell 14 (2003) 1158-1171

$\left[{ }^{29}\right]$ L. Yang, J. Guerrero, H. Hong, D. B. DeFranco, and M. R. Stallcup, Interaction of the tau2 transcriptional activation domain of glucocorticoid receptor with a novel steroid receptor coactivator, Hic-5, which localizes to both focal adhesions and the nuclear matrix, Mol Biol Cell 11 (2000) 2007-2018.

$\left[{ }^{30}\right]$ N. Fujimoto, S. Yeh, H. Y. Kang, S. Inui, H. C. Chang, A. Mizokami, and C. Chang, Cloning and characterization of androgen receptor coactivator, ARA55, in human prostate, J Biol Chem 274 (1999) 8316-8321.

$\left.{ }^{31}\right]$ Z. Gao, and L. M. Schwartz, Identification and analysis of Hic-5/ARA55 isoforms: Implications for integrin signaling and steroid hormone action, FEBS Lett 579 (2005) 56515657.

$\left.{ }^{32}\right]$ L. Bongiorno-Borbone, G. Kadare, F. Benfenati, and J. A. Girault, FAK and PYK2 interact with SAP90/PSD-95-Associated Protein-3, Biochem Biophys Res Commun 337 (2005) 641-646.

$\left[{ }^{33}\right]$ J. T. Ferraro, M. Daneshmand, R. Bizios, and V. Rizzo, Depletion of plasma membrane cholesterol dampens hydrostatic pressure and shear stress-induced mechanotransduction pathways in osteoblast cultures, Am J Physiol Cell Physiol 286 (2004) C831-839.

\section{Figure legends}

\section{Figure 1: Tyrosine phosphorylation of focal contact proteins induced by cyclic strain.}

ROS 17/2.8 cells were lysed immediately (0'), 30 min (30') or 240 min (240') after the end of strain. Lysates were immunoprecipitated with anti-phosphotyrosine rabbit polyclonal antibody 
and immunoblotting with anti-P-tyr (PY99) antibody (Fig 1A). Four predominant bands were seen at 125, 116, 68 and $51 \mathrm{KDa}$ showing a significant increase in phosphotyrosine after strain. (Control): unstretched control plate. Lysates were immunoprecipitated with anti-FAK (Fig 1B) or with anti-PYK2 (Fig 1C) antibodies and immunoblotted with anti-Ptyr, anti-FAK or anti-PYK2 antibodies as indicated. Quantifications of FAK and PYK2 phosphorylation were performed by densitometric scanning of the bands. The data presented here are representative of at least two separate experiments. Lysates were immunoprecipitated with anti-Paxillin (Fig 1D) and anti-Hic-5 antibodies (Fig 1E) and immunoblotted with anti-Ptyr, anti-Paxillin or anti-Hic-5 antibodies as indicated.

Figure 2: Microscopic views of Paxillin, FAK, HIC-5 and PYK2 immunostaining in strained cells.

Subconfluent monolayers of ROS17/2.8 were subjected to cyclic strain. Cells were then fixed and immunostained immediately after strain (0’), 30 minutes (30’) or 240 minutes (240’) after strain with anti-paxillin (Fig 2A), anti-FAK (Fig 2B), anti-Hic-5 (Fig 2C) and with antiPYK2 antibody (Fig 2D). We observed that in controls and immediately after strain the four proteins were localized at focal contacts. Whatever the timing, Paxillin and FAK remained associated with focal contact proteins, this is in sharp contrast with the redistribution found for HIC-5 that is found cytoplasmic as soon as 30' after strain and clearly associated with fibrillar structures of the cytoskeleton 240 minutes after strain. As for PYK2 wich presented a diffuse (cytoplasmic) and focal contact pattern at 0 ' and 240', we observed a complete diffusion of the staining 30' after strain. Bar $10 \mu \mathrm{m}$.

Figure 3: Microscopic views of HIC-5 30' and 240' after cyclic strain. 
Subconfluent monolayers of ROS17/2.8 were subjected to cyclic strain. Cells were then fixed and immunostained 30 minutes (30’) or 240 minutes (240') after strain with anti-Hic-5. Same field is illustrated in (A and B), Visualisation of Hic-5 in the nuclear plane (Fig. 3A) illustrated that Hic-5 was not present is the nucleus and that punctuated staining observed 30' after cyclic strain were detected in apical structures of the cells (Fig. 3B). Hic-5 staining 240' after strain illustrated that Hic-5 associated with fibrilllar structures (white arrows) (Fig. 3C). Bars: $10 \mu \mathrm{m}$.

\section{Figure 4: Strain-induced modification of PYK2-containing complexes.}

Lysates from ROS 17/2.8 were immunoprecipitated using anti-PYK2 (A, C, D) or anti-Hic-5 (B) antibodies. The immune complexes were then Western-blotted with anti-Hic-5, antipaxillin or anti-FAK antibodies as indicated. We found that under cyclic strain, PYK2 increased its association with FAK, and HIC-5 at the expense of HIC-5/Paxillin complex.

\section{Figure 5: Proposed mechanism of focal contact activation.}

Based on our results, we proposed that in unstrained conditions, a complex between Paxillin (PAX), HIC-5 and PYK2 inactivated focal contact by preventing the formation of a FAK/PYK2 complex and by maintaining inactive PAX in a Pax/HIC-5 complex. In strained conditions the severing of HIC-5 outside focal contact associated with the closer association of FAK and PYK2 could explained how cyclic strain activated focal adhesion leading to MAPK dependent pathways. 


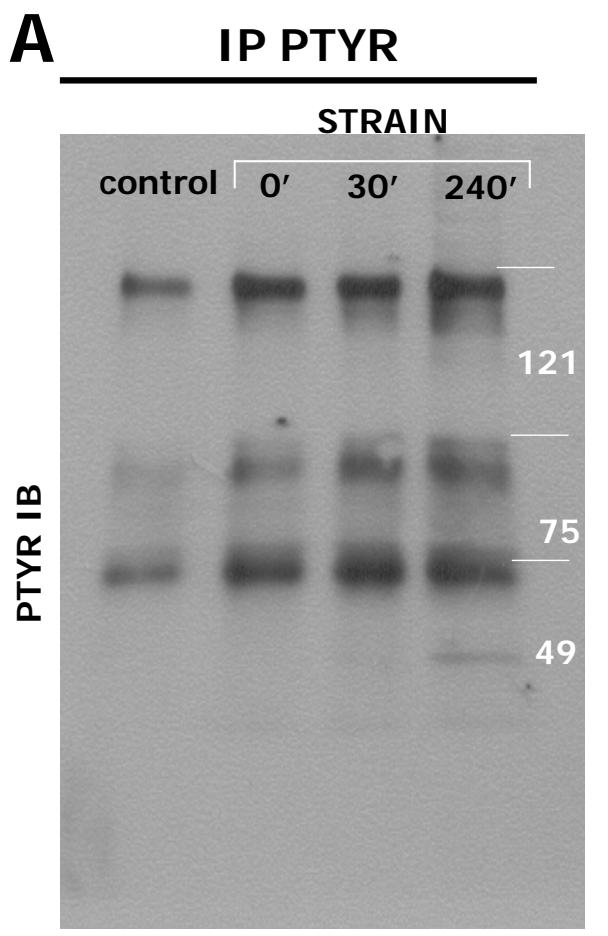

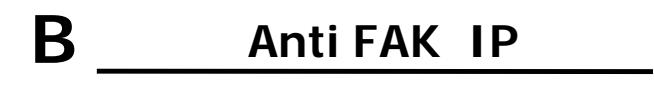
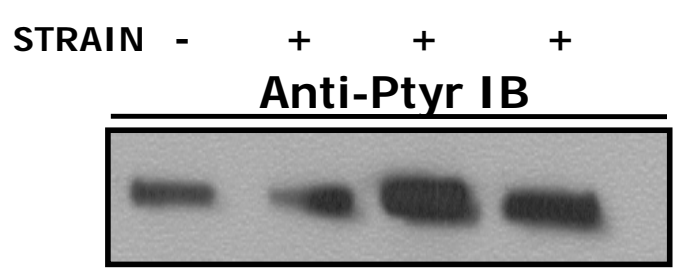

Anti-FAK I B
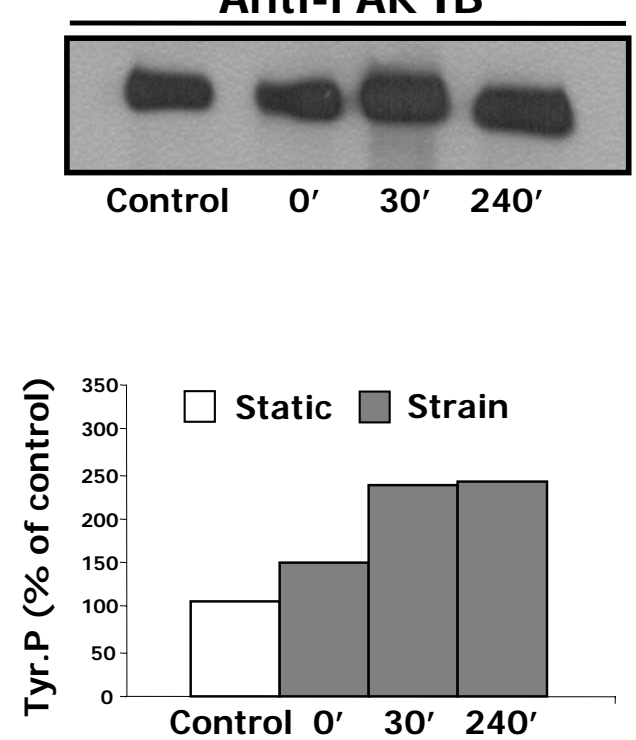

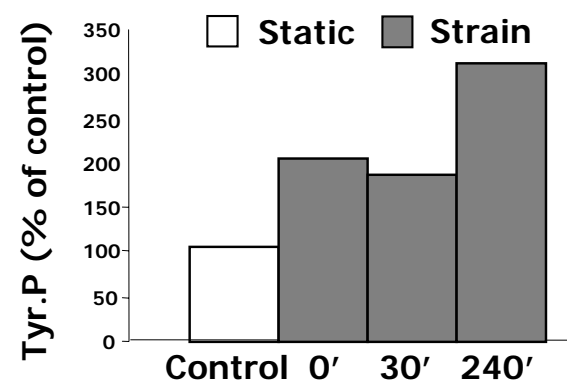

C Anti PYK2 I P

STRAI N - $+\quad+\quad+$

Anti-Ptyr I B

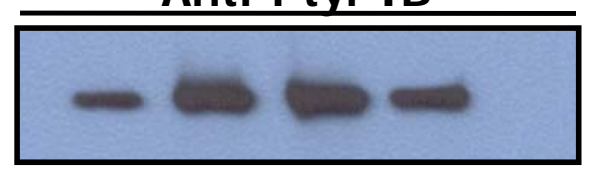

Anti-PYK2 I B

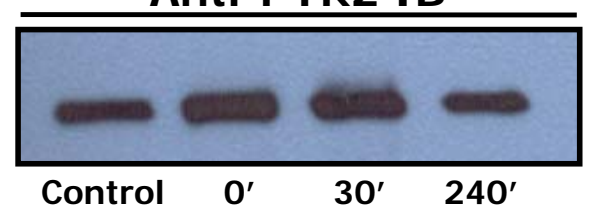

Control 0' 30' 240'

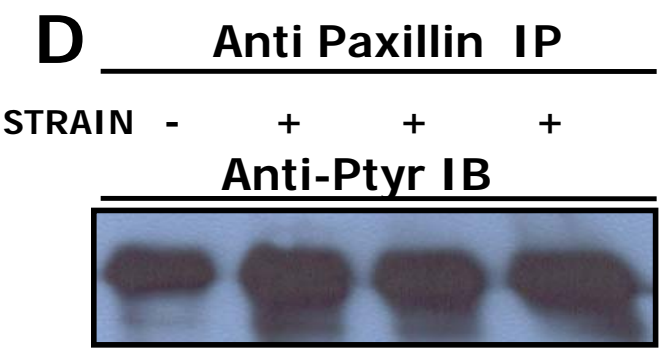

Anti-Paxillin I B

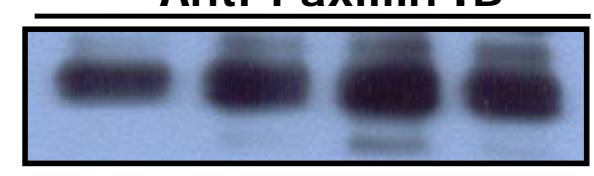

Control 0' $^{\prime}$ 30' 240'

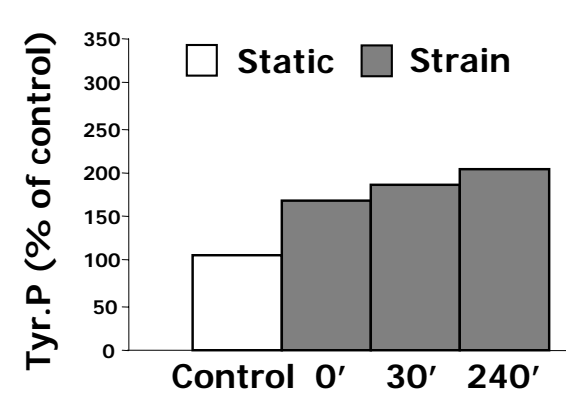

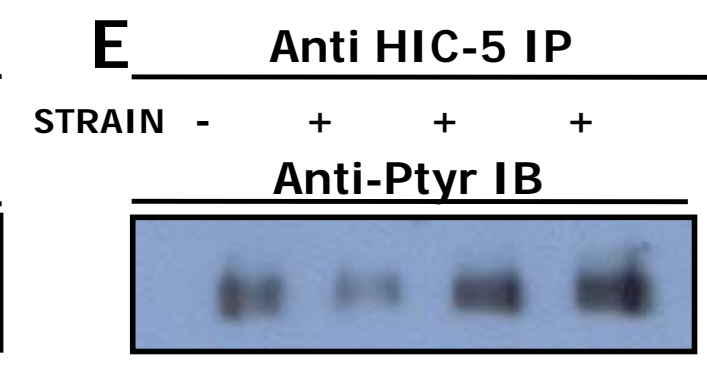

Anti-HI C-5 I B
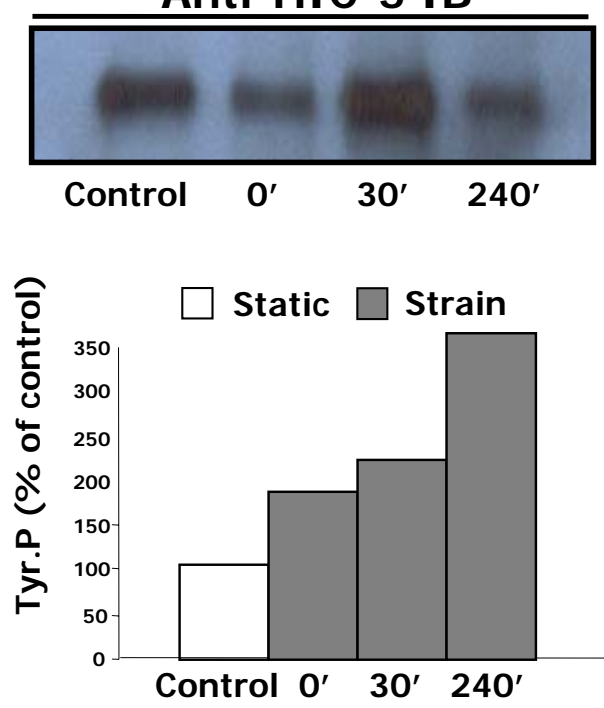


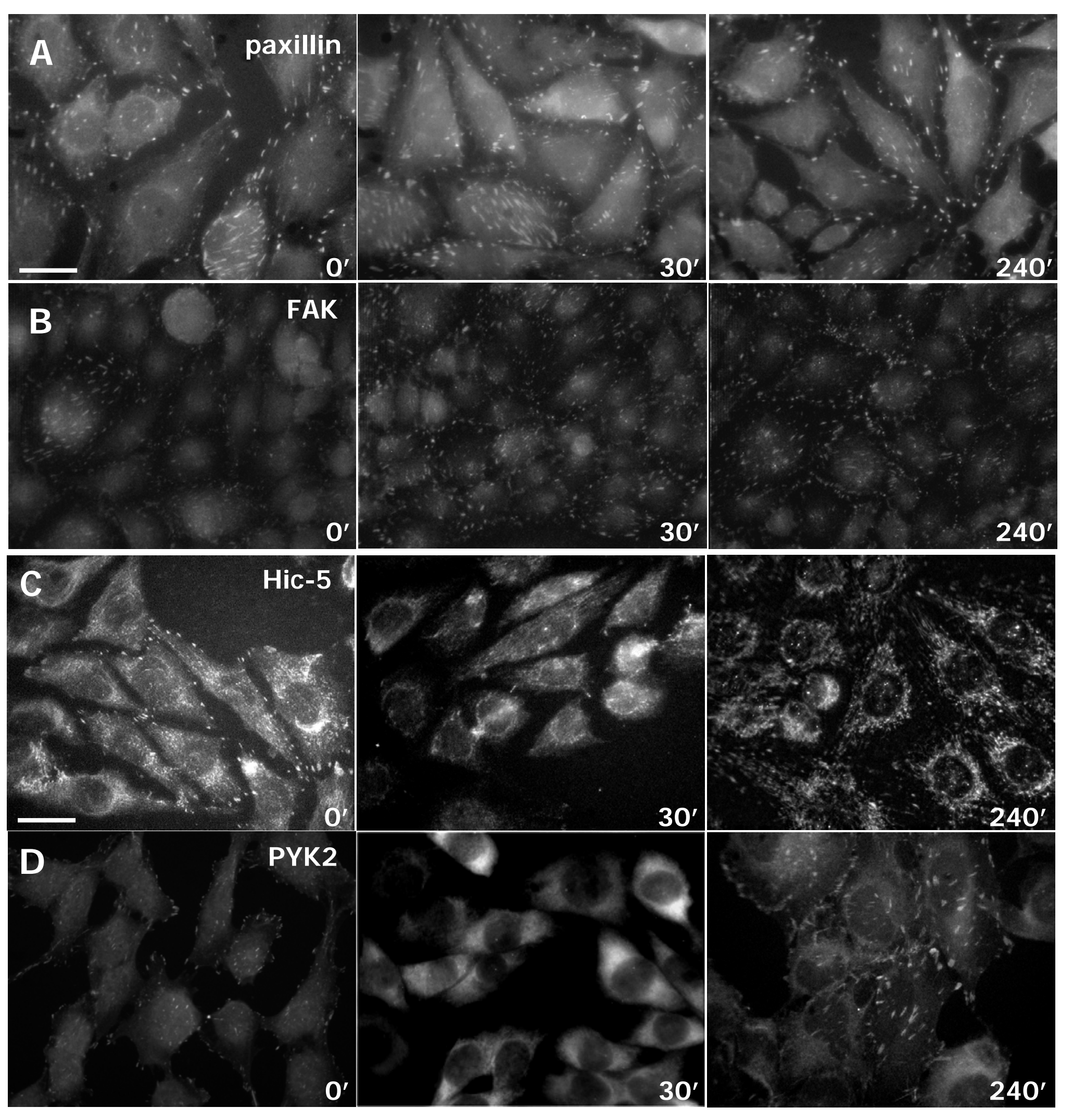

Fig. 2 

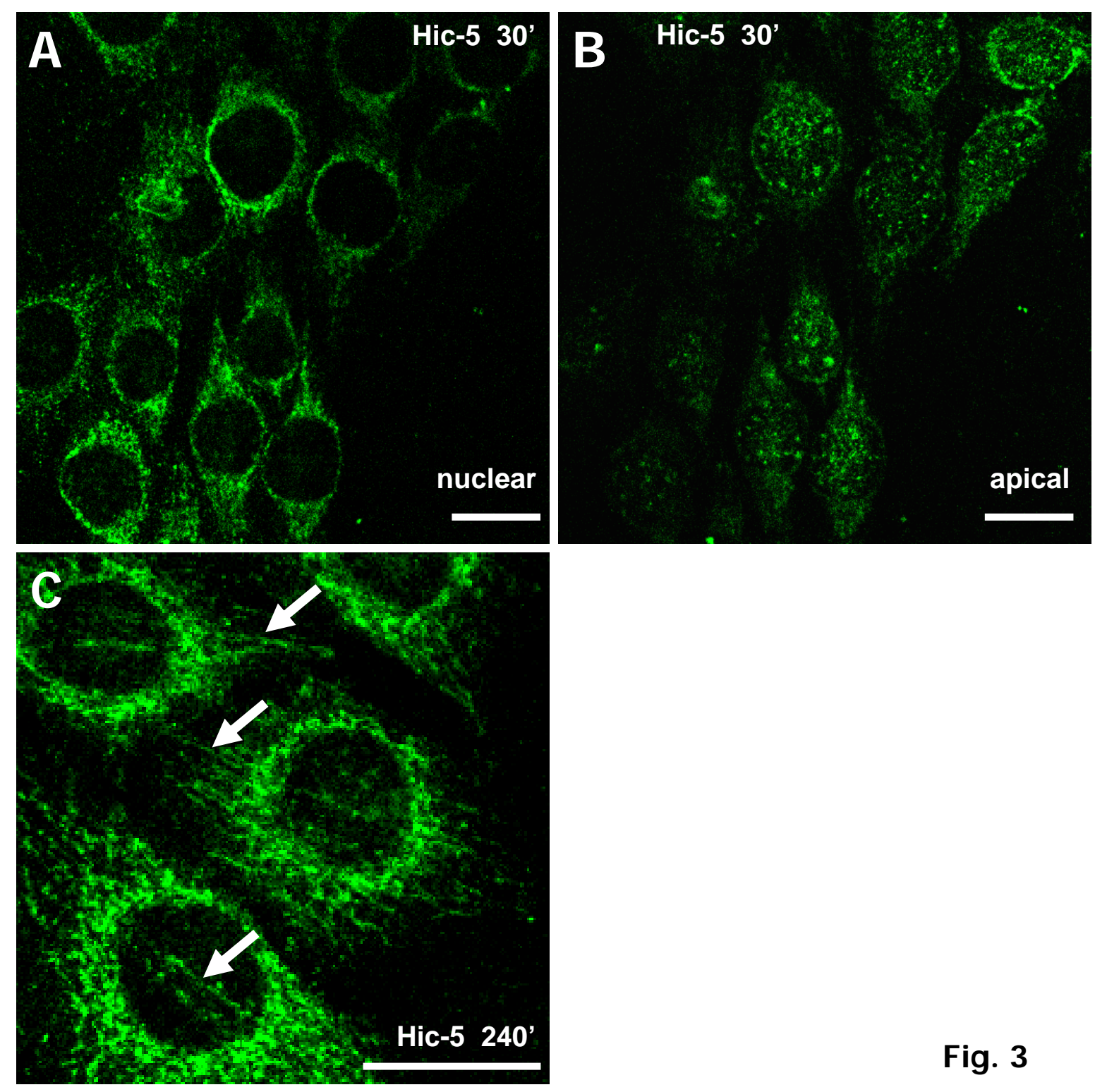

Fig. 3 
A

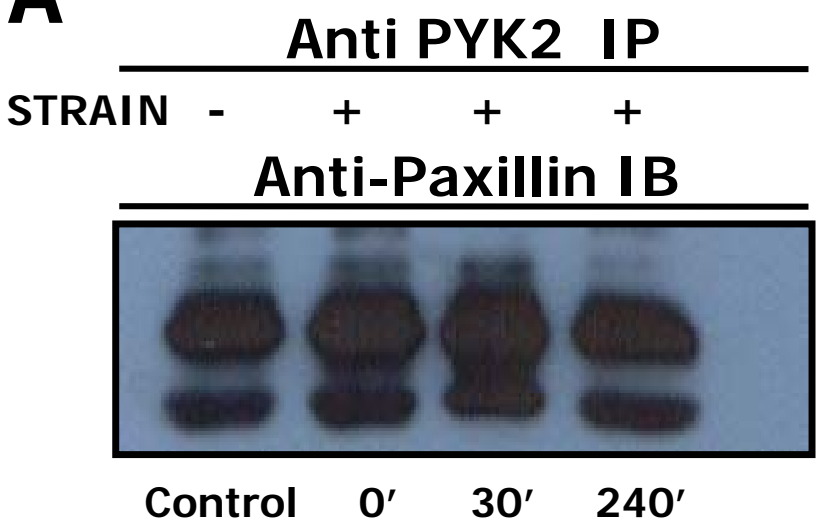

C STRAI N

Anti PYK2 IP $+\quad+\quad+$ Anti-Hic-5 I B

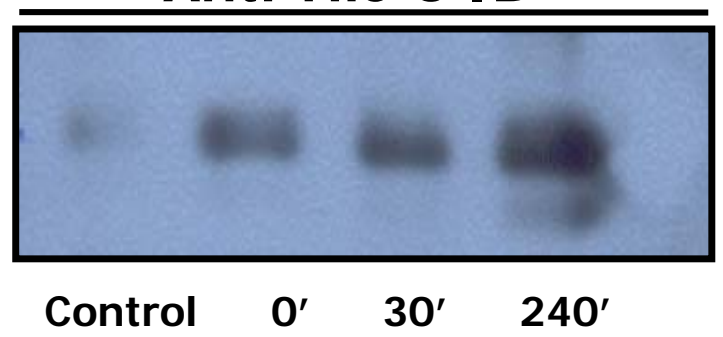

B
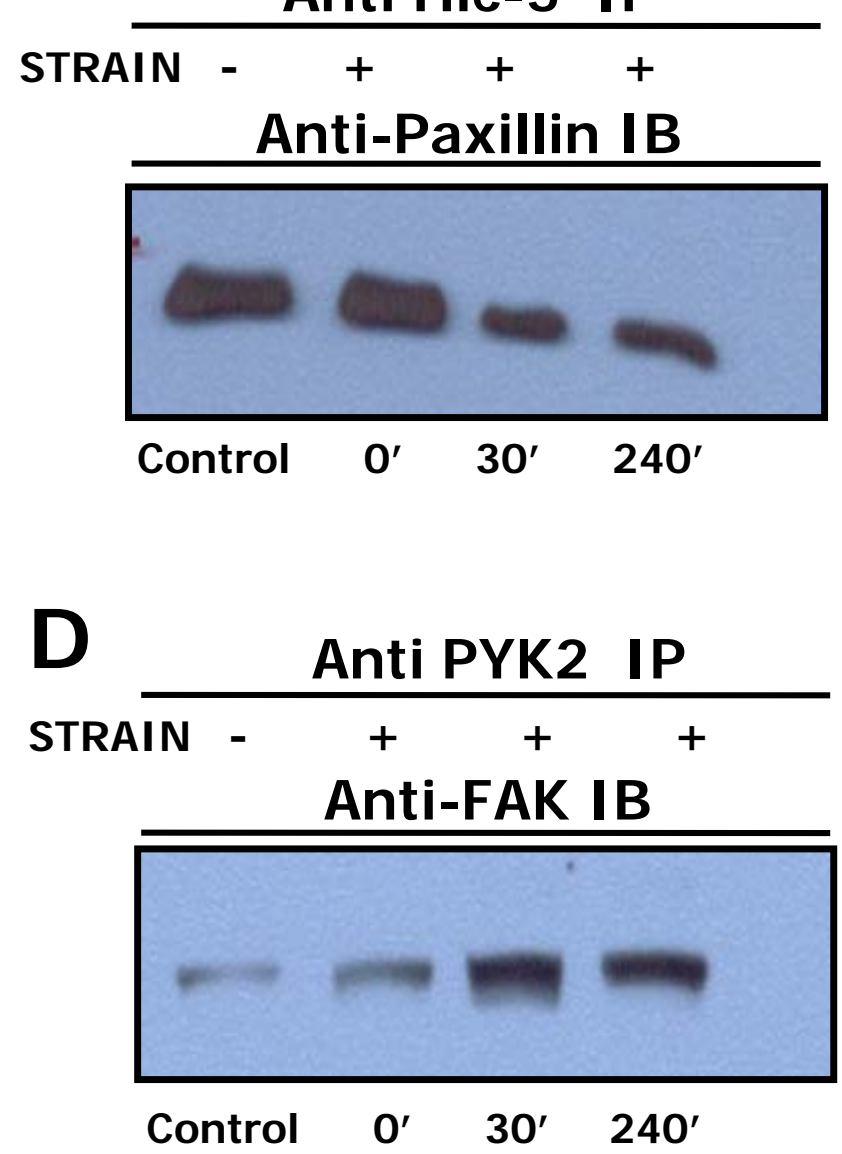


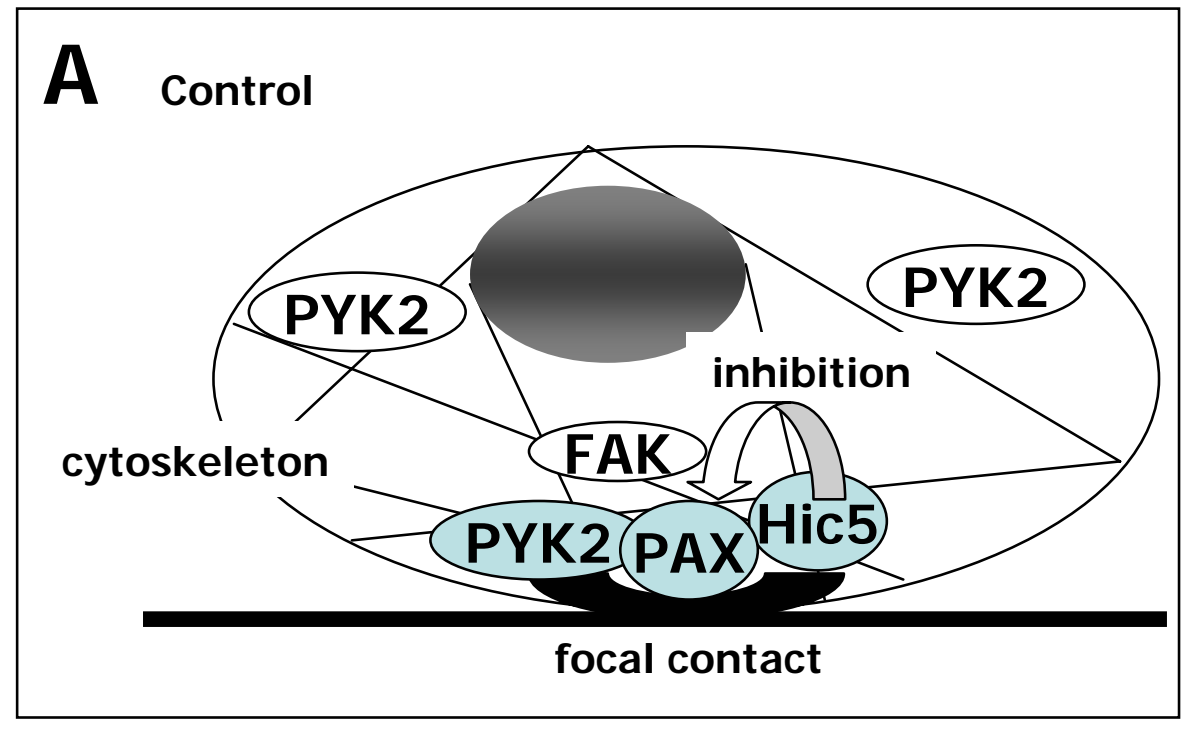

$B$ 240'

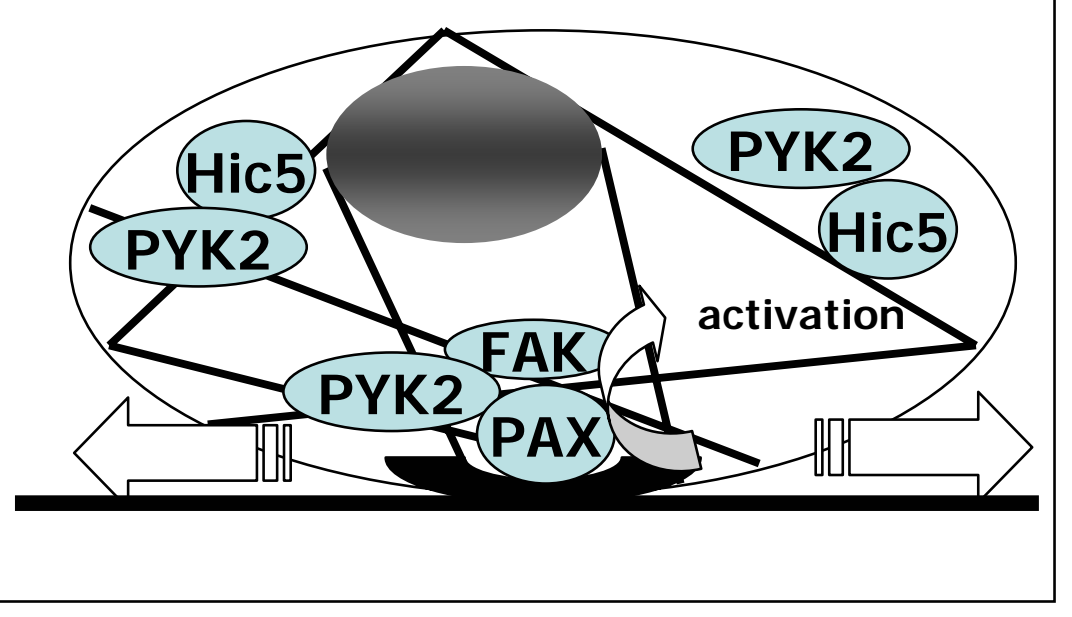

Fig. 5 